\title{
DASI GANDA ( WADAH PROMOSI DENGAN GAYA BERBEDA ) DI ERA INDUSTRI 4.0 DENGAN PEMANFAATAN PLATFORM BAGI PENGRAJIN SANDAL C'KER
}

\author{
Galang Abdul Aziz'1), Nadila Al Azhar ${ }^{1)}$, Fauzan Aufa Pradiva ${ }^{1)}$, Oryz Agnu Dian Wulandari") \\ ${ }^{1) B i s n i s ~ D i g i t a l, ~ B i s n i s ~ d a n ~ I I m u ~ S o s i a l, ~ U n i v e r s i t a s ~ A m i k o m ~ P u r w o k e r t o, ~ P u r w o k e r t o, ~ J a w a ~ T e n g a h, ~ I n d o n e s i a ~}$ \\ Corresponding author : Oryz Agnu Dian Wulandari \\ E-mail : oryzdian@amikompurwokerto.ac.id
}

Diterima 11 Oktober 2020, Direvisi 19 Oktober 2020, Disetujui 19 Oktober 2020

\begin{abstract}
ABSTRAK
UMKM di Indonesia saat ini memiliki pengaruh yang besar dalam membantu meningkatkan kemajuan bangsa. Perkembangan UMKM tersebut, dapat berkembang jauh lebih pesat apabila UMKM dalam pemasarannya mengikuti perkembangan saat ini yaitu dengan menggunakan digital marketing agar dapat terjangkau diberbagai wilayah bahkan hingga ke tingkat Internasional. Kegiatan pemasaran dapat dinilai berhasil apabila produk yang dijual dapat menembus pasaran hingga ke tingkat Internasional. Pemanfaatan dengan menggunakan digital marketing dapat dilakukan dengan memanfaatkan media sosial, marketplace, website sebagai media dalam melakukan berbagai transaksi baik promosi, menjual produk maupun digunakan sebagai kegiatan transaksi jual - beli bagi pelaku usaha. Kabupaten Banyumas terdapat berbagai UMKM salah satunya adalah pengrajin sandal bandol. Pemasaran sandal bandol di Kabupaten Banyumas saat ini masih menggunakan cara tradisional, sehingga masih banyak masyarakat di Indonesia yang belum mengetahui bahkan mengenal produk sandal bandol. Mitra dari kegiatan pengabdian kami yakni pengrajin Sandal Bandol C'KER di Kabupaten Banyumas milik Bapak Subandi. Tujuan dari pengabdian kami yaitu untuk mengembangkan pemasaran digital bagi pengrajin sandal bandol agar dapat meningkatkan penjualan serta pendapatan bagi pelaku usaha dengan cara membuat wadah promosi dengan memanfaatkan media sosial yang sudah ada serta platform yang telah kami miliki. Metode yang kami gunakan yaitu dengan melakukan wawancara secara daring dikarenakan situasi covid saat ini untuk memperoleh hasil dari perbedaan sebelum dan sesudah dilakukan pendampingan oleh DASI GANDA. Hasil dari kegiatan pengabdian kami setelah melakukan pendampingan kepada pengrajin sandal bandol selama 4 bulan yakni bulan april sampai dengan bulan juli adalah adanya peningkatan penjualan serta respon positif dari masyarakat untuk mengenal jauh produk sandal bandol. Hasil tersebut diperoleh dari hasil wawancara dengan mitra yakni Bapak Subandi yang menyatakan bahwa sebelum dilakukan pendampingan oleh DASI GANDA dengan sistem penjualan secara offline, dapat menjual sandal bandol dalam 1 bulan sebanyak 4-6 buah tetapi setelah dilakukan pendampingan oleh DASI GANDA, dalam 1 bulan dapat menjual Sandal Bandol C'KER sebanyak 8-10 pasang sandal bandol.
\end{abstract}

Kata kunci: UMKM; pemasaran digital; sandal bandol.

\begin{abstract}
UMKM in Indonesia currently have a big influence in helping to improve the progress of the nation. The development of these UMKM can develop much more rapidly if UMKM in their marketing follow current developments, namely by using digital marketing so that they can be reached in various regions even to the international level. Marketing activities can be considered successful if the products being sold can penetrate the market to the international level. Utilization using digital marketing can be done by utilizing social media, marketplaces, websites as media in carrying out various transactions, both promotions, selling products and being used as buying and selling transactions for business actors. Banyumas Regency has various UMKM, one of which is a bandol sandal craftsman. Currently, the marketing of bandol sandals in Banyumas Regency still uses traditional methods, so that there are still many people in Indonesia who do not know or even know about bandol sandals. The partner of our service activities is the Sandal Bandol C'KER craftsman in Banyumas Regency owned by Mr. Subandi. The goal of our service is to develop digital marketing for bandol sandal craftsmen in order to increase sales and income for business actors by creating a promotional platform by utilizing existing social media and the platforms we already have. The method we use is to conduct online interviews due to the current covid situation to obtain results from differences before and after assistance by DASI GANDA. The result of our service activities after mentoring bandol sandal craftsmen for 4 months, from April to July, is an increase in sales and a positive response from the community to get to know the bandol sandal products.
\end{abstract}


These results were obtained from the results of interviews with partners, namely Mr. Subandi, who stated that before assistance by DASI GANDA with an offline sales system, he could sell 4-6 bandol sandals in 1 month but after assistance by DASI GANDA, within 1 month sells C'KER Bandol Sandals as many as $8-10$ pairs of bandol sandals.

Keywords: UMKM; digital marketing; bandol sandals.

\section{PENDAHULUAN}

Pemerintah Indonesia saat ini telah fokus dalam mengembangkan UMKM di berbagai daerah. UMKM di Indonesia dinilai mampu memberikan kontribusi nyata bagi Indonesia dengan menggerakan pertumbuhan ekonomi bagi Indonesia, selain itu pembangunan melalui sektor UMKM menjadi prioritas yang diharapkan mampu menjadi instrumen ekonomi yang berkeadilan serta memberikan kesejahteraan yang lebih merata. Menurut Sukirno (2004), menyatakan bahwa membangun ekonomi merupakan pertumbuhan ekonomi yang diikuti perubahan dalam aspek lain yakni dalam bidang perekonomian, seperti perkembangan pendidikan, perkembangan kualifikasi SDM, perbaikan teknologi dan meningkatnya taraf kemakmuran masyarakat. Pakpahan (2020), menyatakan bahwa UMKM menjadi tulang punggung Indonesia dalam perekonomian nasional yang dapat mempengaruhi beberapa aspek yakni produksi, pendapatan dan juga tenaga kerja. Saat ini UMKM di Indonesia telah mengalami peningkatan yang signifikan, hal tersebut berdasarkan informasi yang diperoleh dari website kominfo yang menyatakan bahwa di tahun pelaku UMKM sebanyak 58,97 yang kemudian di tahun 2019 mengalami kenaikan $5 \%$ menjadi 59,2 juta pelaku usaha. Dari 59,2 juta pelaku usaha ditahun 2019, sebanyak 3,79 juta pelaku usaha UMKM sudah memanfaatkan platform online dalam melakukan pemasaran produk. Program UMKM Go Online yang telah dibentuk oleh pemerintah memiliki tujuan untuk mempercepat transformasi UMKM yang awalnya dalam proses kegiatan pemasaran masih secara tradisional berubah menjadi UMKM dengan menggunakan media digital agar dapat terjangkau lebih luas diberbagai daerah. Ascharisa (2018), menyatakan bahwa metode dalam berkomunikasi dalam kegiatan pemasaran yang sebelumnya bersifat tradisional saat ini telah berkembang serta terintegrasi dengan menggunakan media digital dalam kegiatan pemasaran. Wardhana (2015), berpendapat bahwa digital marketing sebagai suatu kegiatan pemasaran yang menggunakan media berbasis internet. Prabowo (2018), menyatakan bahwa digital marketing dapat membantu perusahaan atau pelaku usaha dalam memperluas pasar.
Transformasi UMKM dengan cara tradisional dalam kegiatan pemasaran saat ini berubah menggunakan media digital, hal tersebut didorong dengan berkembangnya Indonesia yang saat ini telah masuk pada Era Revolusi Industri 4.0 serta harus melakukan perubahan dengan mengikuti perkembangan zaman. Andriani (2017), menyatakan bahwa dalam industry 4.0 terjadi proses digitalisasi untuk semua aspek kehidupan dari sebuah revolusi yakni inovasi. Dudi Sudrajat (2017), menyatakan bahwa UMKM harus didorong untuk dapat memanfaatkan ekonomi secara digital atau e-commerce dengan tujuan untuk memperluas pasar. Hardilawati (2019), menyatakan bahwa e-commerce memiliki pengaruh positif terhadap peningkatan kinerja pemasaran dan pendapatan UMKM. Perkembangan teknologi di Indonesia untuk meningkatkan pemasaran dan penjualan dapat dilakukan dengan memanfaatan media sosial, marketplace, website sebagai media dalam melakukan berbagai transaksi baik promosi, menjual produk maupun digunakan sebagai kegiatan transaksi jual - beli bagi pelaku usaha. Menurut Stelzener (2012), menyatakan bahwa media social dapat membantu pelaku UMKM dalam kegiatan memasarkan produknya. UMKM di Kabupaten Banyumas saat ini masih banyak yang belum sadar tentang teknologi yang berkembang dan dapat digunakan sebagai media promosi serta transaksi jual beli, selain itu mereka masih belum mengerti bagaimana cara memanfaatkan teknologi sebagai media transaksi serta promosi. Hal inilah yang mendasari kami ingin menciptakan jasa sebagai wadah promosi dengan gaya berbeda (DASI GANDA) yang dapat digunakan bagi pelaku UMKM di kabupaten Banyumas agar dapat mengembangkan usahanya dengan mempromosikan produknya melalui jasa yang telah kami rancang dengan memanfaatkan berbagai media sosisal, marketplace, website atau yang dapat membantu serta memberikan kemudahan bagi pelaku UMKM dalam meningkatkan penjualan. Jinling (2019), menyatakan bahwa dengan adanya internet proses pemasaran dan penjualan dapat dilakukan kapan saja tanpa adanya Batasan ruang dan waktu. Tujuan dari pengabdian kami yaitu untuk mengembangkan pemasaran digital bagi pengrajin sandal bandol agar dapat 
meningkatkan penjualan serta pendapatan bagi pelaku usaha dengan cara membuat wadah untuk media promosi dengan memanfaatkan media sosial yang sudah ada serta platform yang telah kami miliki. Sehingga untuk mengetahui peningkatan penjualan kami menggunakan metode wawancara secara daring dikarenakan situasi covid saat ini untuk memperoleh hasil dari perbedaan sebelum dan sesudah dilakukan pendampingan oleh DASI GANDA.

\section{METODE PELAKSANAAN}

Mitra dari kegiatan pengabdian kami yakni pengrajin Sandal Bandol C'KER di Kecamatan Banaran, Kabupaten Banyumas milik Bapak Subandi. Metode yang kita gunakan untuk pengabdian ini adalah dengan melakukan wawancara guna memperoleh informasi keadaan mitra saat ini sebagai sarana kami dalam membantu permasalahan mitra selain itu kami memberikan sosialisasi mengenai platform DASI GANDA yang akan kami lakukan untuk membantu mitra. Kegiatan pengabdian ini diawali dengan berbagai tahap pelaksanaan yakni, 1) penyusunan konsep, penyusunan konsep dilakukan agar kegiatan pengabdian dapat berjalan sesuai rencana dan tujuan yang diharapkan. Pada tahap pertama kegiatan yang dilakukan adalah merencanakan fitur - fitur apa saja yang akan ditampilkan ke dalam web, desain dari web, dan media apa saja yang akan digunakan untuk promosi. 2) membuat platform dan website, langkah utama dalam pembuatan platform dan website adalah menentukan nama platform yakni DASI GANDA (Wadah Promosi Dengan Gaya Berbeda) yang diharapkan dapat dimanfaatkan oleh pelaku usaha UMKM sandal bandol sebagai alat untuk melakukan kegiatan pemasaran secara online. 3) tahap pengerjaan, pada tahap ini terdapat dua proses yang harus dilalui yakni:

a. Proses Promosi

Sebelum kegiatan pemasaran, ada baiknya mengecek kembali detail produk yang akan di promosikan agar tidak terjadi kesalahan dalam memasukkan data. Setelah proses pengecekan selesai kemudian kegiatan promosi dan pemasaran suatu produk dapat dilakukan dengan memanfaatkan platform serta website yang telah kami rancang.

b. Proses Pemesanan

Pemesanan dapat dilakukan secara online dengan memanfaatkan platform yang telah kami rancang melalui facebook, instagram, website serta memanfaatkan marketplace yang telah berkembang dan kemudian terhubung dengan nomor whatsapp pelaku usaha UMKM sandal bandol di Kabupaten Banyumas.

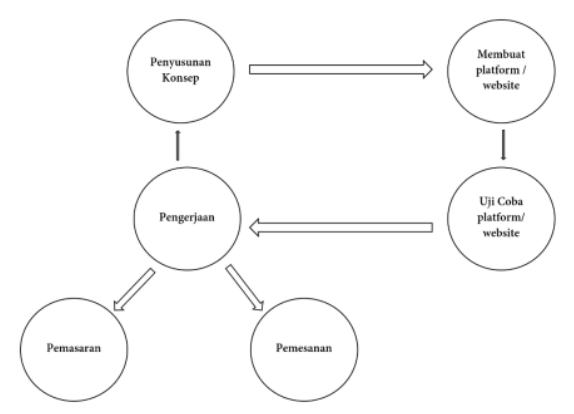

Gambar 1. Langkah Pelaksanaan Pengabdian

Gambar 1 menunjukan langkah kami dalam melaksanakan pengabdian kepada pengrajin sandal bandol C'KER. Pada gambar tersebut dijelaskan pada langkah awal adalah Menyusun sebuah konsep. Penyusunan konsep ini dilakukan dengan tujuan membuat rancangan suatu konsep dalam membantu mitra kami. Konsep disusun agar dalam kegiatan pengabdian dapat berjalan sesuai dengan tujuan dan memiliki manfaat bagi mitra. Langkah selanjutnya adalah membuat platform atau website, pembuatan platform ini digunakan sebagai sarana pemasaran sandal bandol guna meningkatkan penjualan dan pendapatan bagi mitra. Langkah ketiga yakni uji coba platform, uji coba ini dilakukan untuk mengetahui apakah

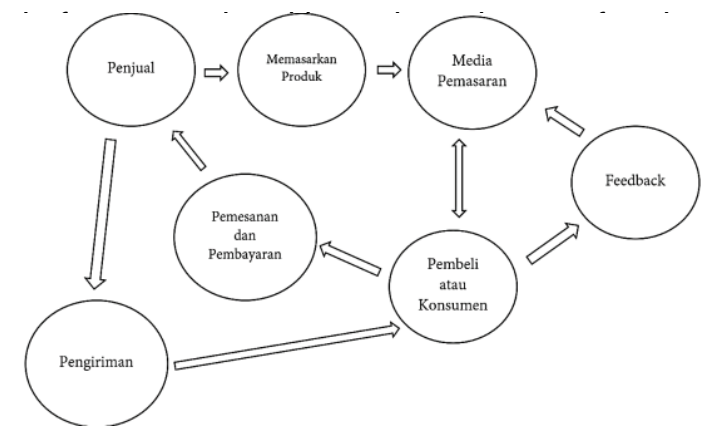

Gambar 2. Proses Pemesanan

Gambar 2 menunjukan proses pemesanan sandal bandol C'KER melalui platform DASI GANDA. Gambar tersebut menjelaskan bahwa penjual mempromosikan produk sandal bandol C'KER melalui platform yang telah kami sediakan, kemudian konsumen atau pembeli memberikan feedback kepada kami untuk mengetahui stock produk sandal bandol C'KER yang telah kami promosikan. Kemudian setelah ada kesepakatan, pembeli melakukan pemesanan dan pembayaran. Setelah pemesanan dan pembayaran dilakukan, kemudian kami dari DASI GANDA melakukan 
peckaging untuk kemudian mengirimkan sandal bandol C'KER ke alamat pembeli maupun konsumen yang kemudian setelah pembeli menerima produk, pembeli melakukan penilaian kepada produk sandal bandol C'KER dan juga pelayanan yang kami berikan.

\section{HASIL DAN PEMBAHASAN}

Pengabdian ini dilaksanakan sesuai dengan jadwal yang telah ditentukan yakni pada awal bulan april untuk menyusun konsep platform yang akan kami rancang dengan tujuan sebagai wadah untuk memfasilitasi pengrajin UMKM sandal bandol dalam melaksanakan kegiatan pemasaran. Setelah konsep dirancang dengan baik, selanjutnya adalah membuat media platform dan website yang dapat di manfaatkan pengrajin sandal bandol dalam meningkatkan penjualan. Sebelum platform dan website yang kami rancang digunakan oleh pengrajin sandal bandol, maka kami mengenalkan serta mempromosikan platform kita kepada khalayak umum agar masyarakat mengerti platform yang kita miliki. Kemudian tahap selanjutnya adalah pengerjaan yang terdiri dari proses promosi dan pemesanan. Proses promosi sandal bandol dapat dilaksanakan dengan mengambil gambar produk sandal bandol kemudian gambar tersebut ditampilkan pada platform yang telah kami rancang dengan memberikan spesifikasi dan harga produk. Proses pemesanan dilakukan dengan cara menghubungkan langsung ke nomor pengrajin sandal bandol melalui whatsapp untuk kemudian tercipta adanya transaksi jual - beli, kemudian proses pembayaran tergantung kesepakatan antara penjual dan pembeli. Platform yang kami miliki untuk memfasilitasi para pengrajin sandal bandol adalah sebagai berikut:

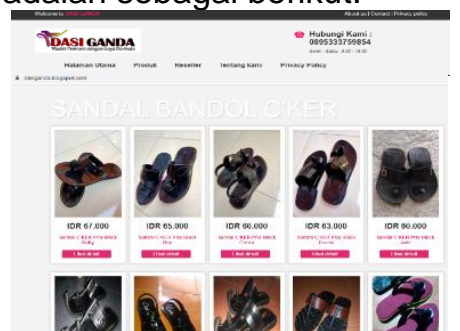

Gambar 3. Website Dasi Ganda

Gambar 3 adalah gambar platform DASI GANDA dengan memanfaatkan website sebagai media pemasaran sandal bandol C'KER. Didalam website tersebut, sudah terdapat beberapa produk sandal yang aka dijual serta terdapat nomor whatsapp DASI GANDA.

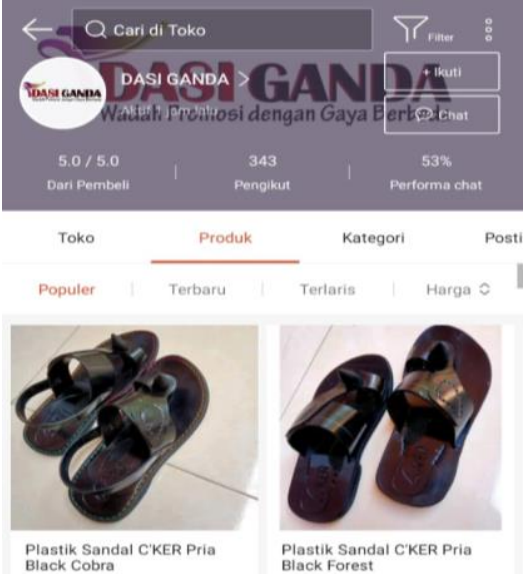

Gambar 4. Dasi Ganda di Marketplace

Gambar 4 adalah bentuk pemasaran sandal bandol C'KER melalui marketplace yang sudah ada di Indonesia yakni Shopee. Didalam marketplace shopee sudah terdapat produk sandal bandol C'KER yang nantinya akan dijual dan dipasarkan kepada masyarakat secara luas.

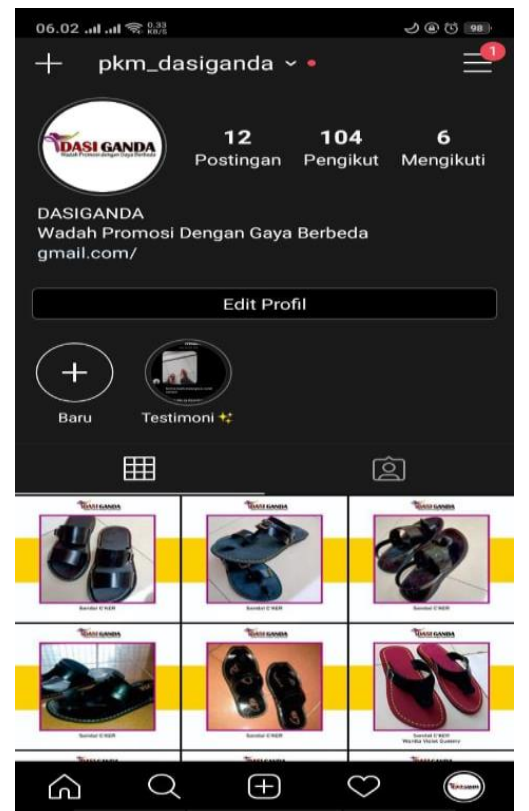

Gambar 5. Platform Dasi Ganda di IG

Gambar 5 menjelaskan tentang IG sebagai media mempromosikan produk sandal bandol C'KER dimana dalam media sosial IG tersebut sudah terdapat beberapa gambar produk sandal C'KER. Proses pemesanan dengan cara menghubungi nomor whatsapp DASI GANDA atau dengan direct massanger IG DASI GANDA. 


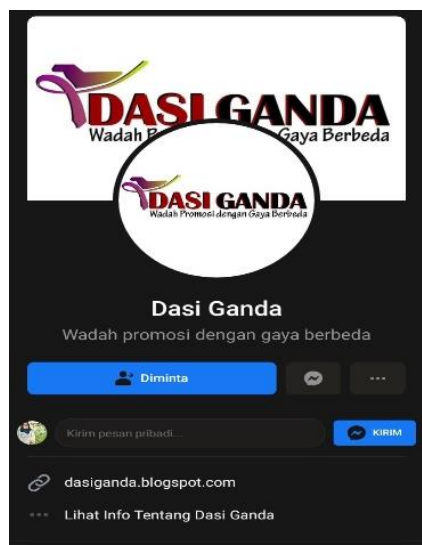

Gambar 6. Platform Dasi Ganda di Facebook

Hasil dari kegiatan pengabdian setelah melakukan pendampingan kepada pengrajin sandal bandol selama 1,5 bulan adalah adanya peningkatan penjualan serta respon positif dari masyarakat. Hasil tersebut diperoleh dari hasil wawancara dengan mitra yakni Bapak Subandi yang menyatakan bahwa sebelum dilakukan pendampingan oleh DASI GANDA dengan sistem penjualan secara offline, dapat menjual sandal bandol dalam 1 bulan sebanyak 4-6 pasang tetapi setelah dilakukan pendampingan oleh DASI GANDA, dalam 1 bulan dapat menjual Sandal Bandol C'KER sebanyak 8-10 pasang. Dibawah ini merupakan gambar respon positif dari pembeli dan produk sandal bandol yang akan dikirimkan kepada pembeli.
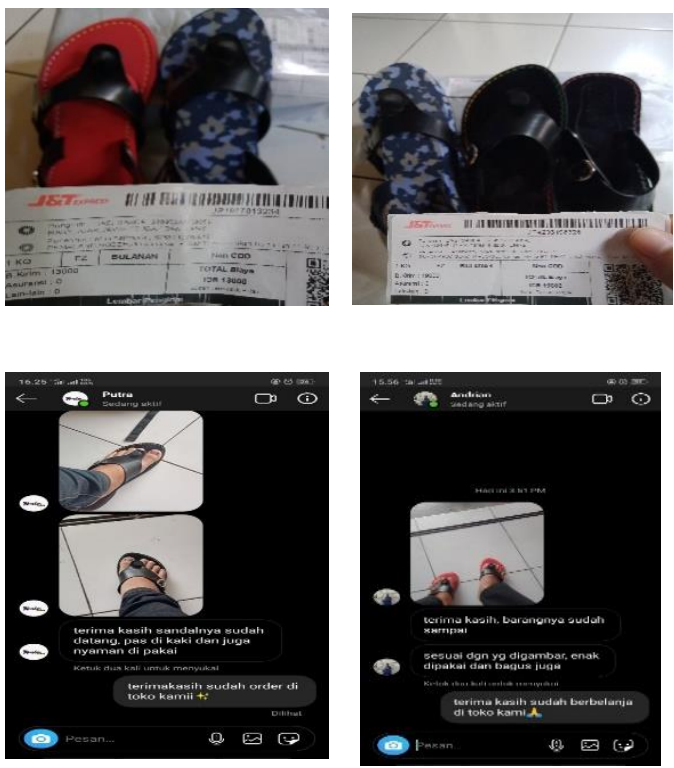

Gambar 7. Penjualan Sandal C'KER Bersama Dasi Ganda

Gambar 7 merupakan salah satu bentuk pelaksanaan DASI GANDA dalam membantu mitra dalam hal ini pengrajin sandal bandol C'KER milik bapak Subandi. Terlihat ada beberapa sampel sandal C'KER yang akan dikirimkan untuk pembeli sandal bandol C'KER.
Selain itu juga terlihat beberapa feedback dari pembeli mengenai sandal bandol C'KER dan juga penilaian dari bentuk pelayanan dari DASI GANDA.

\section{SIMPULAN DAN SARAN}

Simpulan dari kegiatan pengabdian ini adalah DASI GANDA dapat digunakan sebagai wadah dalam melakukan promosi produk sandal bandol. Pengrajin sandal bandol di Kabupaten Banyumas merasakan manfaat dari platform DASI GANDA yakni meningkatnya penjualan serta meningkatnya produksi sandal bandol.

Saran dari kegiatan pengabdian ini adalah lebih mengoptimalkan platform DASI GANDA agar penggunaan serta pemanfaatan bisa lebih efektif dan efisien dan selalu melakukan pembaharuan produk sandal bandol serta memperbaiki fitur pada masingmasing platform agar memudahkan bagi para penggunanya.

\section{UCAPAN TERIMAKASIH}

Ucapan terimakasih kami sampaikan kepada beberapa pihak terkait yakni, teman dosen di Program Studi Bisnis Digital serta seluruh anggota team yang telah memberikan dukungan kepada kami sehingga pengabdian ini dapat berjalan dengan lancar.

\section{DAFTAR RUJUKAN}

Afrilia, A. M. (2018). Digital Marketing Sebagai Strategi Komunikasi Pemasaran "Waroenk Ora Umum" Dalam Meningkatkan Jumlah Konsumen. Jurnal Riset Komunikasi, 1(1), 147-157. https://doi.org/10.24329/jurkom.v1i1.21

Andriani, (2017). Aplikasi Quality Fuction Deployment Untuk Redesign Kontainer Penyimpanan Pada Industri Kemasan Kaleng. Jurnal Teknik Industri. 176-190.

Dudi Sudrajat, (2017). "Menggenjot UMKM Jawa Barat Agar Naik Kelas", Pikiran Rakyat,https://www.pikiranrakyat.com/ ekonomi.

Hardilawati, W.L. (2019). The Role Of Innovation And E-Commerce In Small Business . 83-87.

Jinling, Chang et all. (2009). Modeling ECommerce Website Quality with Quality Function Deployment, IEEE International Conference on Deployment e-Business Engineering. 21-23 Oct. 2009

Pakpahan, A.K. (2020). COVID19 dan Implikasinya Bagi Usaha Mikro, Kecil, Menengah, (April).

Prabowo, W.A. (2018). Pengaruh Digital Marketing terhadap Organizational 
Performance Dengan Intelectual Capital dan Perceived Quality sebagai Variabel Intervening pada Hotel Bintang Tiga di Jawa Timur. Jurnal Manajemen Pemasaran, 12(2)., 101112.https://doi.org/10.9744/pemasaran .12.2.101-112.

Stelzner, M. . (2015). How marketers are using Social Media to grow their businesses. Social Media Examiner, (May), 1-53. https://doi.org/10.1007/BF02653755

Sukirno, S. 2004. Makroekonomi Suatu Pengantar. Rajawali Pers. Jakarta.

Wardhana, A. (2015). Strategi Digital Marketing dan Implikasinya Pada Keunggulan Bersaing UMK di Indonesia. In Seminar Nasional Keuangan Dan Bisnis IV, (April 2015), 327-337. 